\title{
Artigo
}

\section{Massao Ohno: editor independente?}

\author{
Massao Ohno: an independent editor?
}

\author{
Leonardo David de Morais' ${ }^{10}$ \\ 'Centro Federal de Educação Tecnológica de Minas Gerais, Minas Gerais, MG, Brasil
}

\begin{abstract}
RESUMO
A trajetória do editor Massao Ohno esteve voltada predominantemente para a publicação de literatura, especialmente a poesia, gênero esse que, por conta das tiragens reduzidas em relação a outras manifestações literárias, acabou sendo fomentado, em parte significativa, por pequenas editoras, as assim chamadas independentes. Além de selecionar pessoalmente os textos que editou, Massao também foi designer de sua maioria absoluta, ademais de ter empreendido parcerias com outros editores no intuito de ampliar a circulação de sua produção. Nesse sentido, esta investigação propõe pensar se ou como a editora capitaneada por Ohno se configuraria à luz de alguns conceitos relativos à edição e à independência. O objetivo é o de atualizar, ainda que de maneira incipiente, a travessia editorial de Massao Ohno no campo literário brasileiro.
\end{abstract}

Palavras-chave: Campo literário; Edição; Independência; Massao Ohno

\section{ABSTRACT}

The trajectory of the editor Massao Ohno was predominantly focused on the publication of literature, especially poetry, a genre that, due to the reduced circulation in relation to other literary manifestations, ended up being promoted, in a significant part, by small publishers, the so-called independent. In addition to personally selecting the texts he edited, Massao was also the graphical designer of his absolute majority, in addition to having entered into partnerships with other publishers in order to expand the circulation of his production. In this sense, this investigation proposes to think about whether or how the publisher led by Ohno would be configured in the light of some concepts related to editorial pratices and independence. The objective is to update Massao Ohno's editorial journey in the Brazilian literary field, albeit in an incipient way.

Keywords: Literary field; Edition; Independence; Massao Ohno 
A produção editorial do paulista Massao Ohno (1936-2010) esteve voltada predominantemente para a publicação de literatura, sobretudo a poesia, gênero esse que, no Brasil, foi propagado, em parte significativa, por pequenas e médias editoras, as assim chamadas independentes. Além de selecionar pessoalmente os textos que editou, Massao também foi designer da maioria absoluta dos livros por intermédio dele publicados, ademais de ter empreendido parcerias com outros editores no intuito de ampliar a disseminação de sua produção. Nesse sentido, esta investigação propõe pensar se ou como a editora capitaneada por Ohno se configuraria à luz de alguns conceitos relativos à edição e à independência. $O$ objetivo é o de atualizar, ainda que de maneira incipiente, a travessia editorial de Massao Ohno no campo literário brasileiro.

A trajetória de Massao Ohno como editor teve início nos estertores da década de 1950, quando deixa a odontologia - profissão que exerceu por apenas dois anos - e adquire uma prensa tipográfica, instalando-se em um casarão na Rua Vergueiro, em São Paulo. Começa a imprimir apostilas para cursinhos prévestibulares em um primeiro momento, mas logo em seguida diversifica seu negócio, passando a se dedicar com vigor à impressão de literatura, sobretudo poesia, gênero de sua predileção. Ainda na época de sua formação, Massao frequentava a Biblioteca Mário de Andrade onde conheceu muitos de seus futuros editados. Em depoimento para o projeto "Memória Oral", concebido pela já citada BMA, Massao confessa que, na impossibilidade de ser poeta - pois achava que não tinha as habilidades literárias necessárias para tal, apesar de ser uma pessoa culta e de aguçada sensibilidade artística - escolheu publicar ele mesmo os autores do gênero que tanto admirava.

Na primeira fase da Editora, que publicou desde sua fundação, nos últimos anos da década de 1950, até 1964, o ano do golpe militar, Massao edita uma série de autores novos, intitulados "Novíssimos" ou "Geração 60". Esse recorte de autores era formado, sobretudo, por jovens poetas e autores da capital paulista, a maioria estudantes universitários, com algumas exceções. A primeira empreitada 
de fôlego empreendida por Massao Ohno nesse sentido foi a edição e publicação de cerca de treze volumes de poesia, prosa e teatro, integrantes da intitulada "Coleção Novíssimos". Nessa coleção, que circulou por meio de um esquema de assinaturas, chegando aos leitores/assinantes via correios, nomes que tentavam se inserir como agentes efetivos no campo literário da época encontraram guarida inicial. Autores como Roberto Piva, Eunice Arruda, Carlos Felipe Moisés e Renata Pallottini, entre outros, marcaram presença nessa coleção que acabou originando uma antologia, a Antologia dos Novíssimos, organizada pelo próprio Massao Ohno e publicada em 1961.

Com o Golpe de 1964, Massao decide se retirar temporariamente de cena. Só voltaria a publicar em 1973. Em 1976, junto ao poeta e crítico Claudio Willer, organiza a "Feira de Poesia e Artes", que ocorreu no Teatro Municipal de São Paulo e acabou gerando por sua vez um selo editorial e uma coleção de livros dos autores que participaram do evento. Foi a partir desse período que Massao começa uma série de parcerias com outros editores: junta-se a nomes como Roswhita Kempf e Lydia Pires e Albuquerque para publicar vários títulos. Também edita com Ênio Silveira, da gigante Civilização Brasileira, a coleção de poesia intitulada "Poesia Sempre". Continuou a editar e a publicar, incansavelmente, durante as décadas de 1980 até 2010, ano em que viria a falecer. Estima-se que, pela Editora Massao Ohno, tenham sido publicados entre 800 e 1000 títulos.

Uma vez entrevisto algo da travessia de Massao no campo literário, cabe ir direto ao ponto que este trabalho propõe analisar. A práxis editorial da qual Ohno se valeu poderia classificar sua Editora como independente? Antes de que tal pergunta seja respondida, há de se apresentar quais são as noções de edição e independência norteadoras deste trabalho. Alguns dos significados mais genéricos relativos ao conceito de edição podem ser encontrados no Dicionário Houaiss: "ação ou efeito de editar; atividade do editor; reprodução, publicação e difusão comercial por um editor de uma obra (texto, partitura, estampa, disco etc.) [...]" (HOUAISS, 2009). 
No volume $\mathbf{O}$ que é editora?, de Wolfgang Knapp, seu autor apresenta também uma visão mais generalizada dessa atividade:

Etimologicamente, editar vem de parir, dar à luz, tornar público. É nesse sentido que o termo hoje é usado para aquelas empresas que tornam públicos pensamentos, conhecimentos, ideias, técnicas, etc., em forma impressa (ou gravada), em várias cópias (KNAPP, 1986, p. 17).

Interessante notar que, sob essa perspectiva mais generalista trazida pelo estudioso, o ato de editar pode ser visto como ação que visa tornar público aquilo que, a princípio, jazia no terreno do privado, do íntimo, da abstração: pensamentos, ideias, técnicas. Sem dúvida, ecos do Iluminismo - tais como a defesa da liberdade da economia a partir da oferta e da procura ou a organização do conhecimento de forma objetiva - ainda podem ser percebidos nessa prática.

Na obra A construção do livro, Emanuel Araújo busca apresentar a seus leitores considerações sobre o conceito de edição partindo da intervenção do seu artífice, o editor, nos originais a serem publicados.

O trabalho sobre o original não pode alterar muito esse componente básico do autor a que se chama 'estilo'. Desde logo, por conseguinte, convém reconhecer os elementos intrínsecos da forma com que se apresenta o texto, vale dizer, a própria estrutura das orações, sua concatenação, seu ritmo, sua fluência, seu efeito, sua correção, seu estilo enfim. Nessa medida, a liberdade do editor, seu limite de ação, é exíguo, mas essa liberdade existe e deve ser usada. [...] A margem de atuação do editor, no sentido mais amplo, é proporcional à finalidade intrínseca do texto, de qualquer texto: a comunicação escrita, a mensagem visual de cada frase, de cada linha, de cada página. Em outras palavras, a principal tarefa do editor de texto em relação ao original consiste em veicular esse tipo de comunicação de maneira mais clara possível para o leitor. (ARAÚJO, 1986, p. 61).

Antônio Houaiss, já citado, também se aprofundou na tentativa de definir, a partir da etimologia, qual ou quais seriam exatamente as funções que constituiriam a práxis do editor:

O conceito de autor, no caso em aprêço, deve ser tomado em sentido amplo, abarcando também o de diretor de texto ou editor de texto. Com estas duas expressões, designar-se-ão neste livro os conceitos expressos em inglês por chief editor e editor, opostos a publisher. A este último 
corresponde, normalmente, em francês éditeur, em espanhol editor, em italiano editore, em português "editor" - mas nestas quatro línguas românicas, tomadas a mero título de exemplo, também os vocábulos citados englobam, não raro, a área semântica do inglês editor. Neste livro, "editor" fica, pois, restrito ao seu sentido usual de pessoa sob cuja responsabilidade, geralmente comercial, com o lançamento, distribuição e venda em grosso do livro, ou de instituição, oficial ou não, que, com objetivos comerciais ou sem eles, arca com a responsabilidade do lançamento, distribuição e, eventualmente, venda do livro. À relação supra poder-se-ia acrescentar "compilador", "organizador" e palavras afins, que, se não implicam o cuidado de estabelecer o texto, não merecem referência para o problema vertente. (HOUAISS, 1968, p. 22).

Percebe-se que, à função moderna do editor, geralmente, tem sido associada uma série de atividades que se intercruzam praticamente de forma indelével: selecionar, revisar, diagramar, lançar, distribuir, vender, e, também em alguns casos, compilar e organizar os conteúdos a serem publicados. Essa especificidade configura tal práxis como um fazer complexo e multifacetado, constituído a partir da circunvolução de múltiplos saberes. Laurence Hallewell também propôs uma divisão e classificação das figuras que exercem o controle da atividade editorial. Segundo o pesquisador britânico, no Brasil, foi a partir da época da abertura, ao fim do período ditatorial instaurado desde meados da década de 1960,

que a indústria editorial mostrou sua maturidade com a divisão de funções entre o diretor da empresa editorial, o editor tradicional (em inglês, publisher), e o "gerente editorial" (para os americanos e ingleses, o verdadeiro editor) que cuida da escolha de manuscritos e de sua revisão e transformação em textos prontos a serem lançados. (HALLEWELL, 2017, p. 737).

Em depoimento, o poeta, professor e crítico Carlos Felipe Moisés, um dos "novíssimos" publicados por Ohno, deslinda um pouco mais a travessia do editor:

Massao foi acima de tudo um artista gráfico, ciente de que o design por ele concebido, sempre virtualmente outro, a cada obra, deveria estar a serviço do livro em causa, brotando naturalmente dos versos que ele lia e amava, com a alma atenta, e não a serviço da arte do design, em si. Por isso, quando o livro saía de sua mesa de trabalho, bem definidos o formato, o papel, a tipologia, a capa, as ilustrações, a diagramação e tudo o mais, era como se sua tarefa estivesse inteiramente cumprida. Dali por diante, não era mais com ele. Massao nunca escondeu certo 
olímpico desinteresse pelo destino que "seus" livros pudessem percorrer, depois que saíssem da gráfica, produzidos em série, para ingressar na banalidade do mundo dos negócios, em que livros também são objetos de compra e venda. Por essa razão, seu legado não pode ser reduzido à quantificação de um mero acervo, pois ocupa um espaço bem mais amplo e valioso, na memória e no espírito da quantidade de artistas gráficos, capistas, ilustradores e editores que ele ajudou a formar, com a ciência do verdadeiro mestre, que conhece melhor do que ninguém a lição: melhor do que ensinar é ensinar a aprender. (MOISÉS apud SILVA, 2019).

Importante salientar na fala do poeta e crítico o fato de que Massao Ohno não poderia ser classificado exatamente como um editor no sentido stricto sensu conforme a descrição proposta por Houaiss, isto é, como um agente voltado especificamente para a parte comercial, mercadológica, de circulação do produto livro, um publisher, mas se aproximaria à função de gerente editorial, voltado às questões de seleção e materialização dos textos em livros, proposta por Hallewell. Massao se notabilizou pela criatividade e excelência dispendidas, por meio do design editorial, à publicação dos textos literários que julgava importantes do ponto de vista estético e relevantes social e culturalmente.

Ainda sob tal perspectiva, cabe evocar mais uma das observações de Carlos Felipe Moisés sobre as práticas editoriais de Massao: “Não era um editor convencional - o forte de Massao Ohno nunca foram os negócios e a distribuição dos exemplares nas livrarias, mas a edição cuidadosa" (MOISÉS apud MELLO, 2009, p. 194). Nesse sentido, se para o poeta e crítico Décio Pignatari “o poeta é um designer da linguagem" (PIGNATARI, 2005, p. 19), pode ser dito que Massao foi um designer da poesia impressa, ou ainda, um "editor/poeta".

Os pesquisadores mexicanos Hernán López Winne e Víctor Malumían trouxeram à luz em sua obra conjunta intitulada Independientes, ¿de qué? (2016), outra interessante taxionomia relativa à prática editorial, também relacionada à figura do editor.

Entre los editores que han invertido su tiempo en organizar el trabajo editorial se encuentra Constantino Bértolo, que fundó una especie de sello independiente - Caballo de Troya - dentro de un conglomerado 
editorial - Random House -. Según su forma de entender la edición, podemos encontrar tres tipos de editores: el "humanista", el "híbrido" y el "capitalista salvaje". (WINNE, MALUMíAN, 2016, p. 2).

Segundo tal classificação, o editor humanista poderia ser descrito como:

[...] un individuo que posee sobrando capital y que, en lugar de invertirlo en una empresa más lucrativa, decide publicar libros a modo de expresión filantrópica. Al liberarse de la necesidad de generar ganancias, obtiene una completa libertad para publicar aquello que le gusta y puede perserguir la más alta calidad sin preocuparse por el retorno de la inversión. Estos editores pueden pensar la edición como un hobbie y no como un modo de subsistencia, lo cual no implica que sus condiciones no sean estupendas, pero sí que las logicas del mercado no los afectan de la misma forma que al resto del sector. (WINNE, MALUMÍAN, 2016, p. 2).

A segunda categoria pensada seria a do editor "capitalista salvaje [...] para el que la publicación está determinada por los benefícios económicos y no por la calidad de los libros. El factor fundamental al momento de decidir si un libro integrará su catálogo no son los méritos intrínsecos sino su capacidad de venta" (WINNE, MALUMÍAN, 2016, p. 3). Já o último tipo de editor, segundo a classificação proposta por Bértolo e resgatada pelos pesquisadores latino-americanos, seria "un híbrido, el capitalista humanista que persigue con el mismo énfasis la calidad y la rentabilidad: la mirada atenta tanto a la rentabilidad como a la calidad de los trabajos que publica" (WINNE, MALUMÍAN, 2016, p. 4).

Haveria, entretanto, algum perfil de editor que pudesse ser considerado próximo do ideal? De acordo com os teóricos aqui mencionados, sim. No texto crítico evocado, o editor "en su definicíon ideal debería ser, a la vez, un especulador inspirado, dispuesto a las apuestas más arriesgadas, y un contador riguroso, incluso un poco parsimonioso", ou seja, um "editor híbrido" (WIN NE, MALUMíAN, 2016, pp. 2-3). Conforme tem sido desvelado, a atuação de Massao Ohno como editor no campo literário foi bastante peculiar. Tal fato pode ser ilustrado, por exemplo, a partir dos comentários de Carlos Felipe Moisés anteriormente apresentados. É perceptível uma preferência de Massao pelas questões estéticas do processo editorial e certa desatenção para com os aspectos comerciais relativos 
a suas publicações, o que poderia aproximá-lo, com alguma reserva, à primeira das categorias ainda em questão.

Contudo, cabe observar que esse aparente desinteresse do editor no tocante aos aspectos de comercialização para com os livros de sua casa editoral não foi tão radical quanto apresentado. As parcerias empreendidas por Massao Ohno com outros editores para otimizar a circulação de seus livros, principalmente a partir de década de 1970, sem abrir mão do envolvimento no processo de design de cada projeto - e que serão comentadas mais adiante nesta tese - poderiam associá-lo à condição de editor híbrido, preocupado tanto com os aspectos estéticos como atento as exigências mercadológicas. Nesse sentido, pode ser deferido a Massao Ohno o título de editor híbrido, uma vez que o cuidado para com a materialização somada à constante busca por parcerias no intuito de otimizar a circulação dos produtos publicados por sua casa editorial apresentam-se como evidências que confirmariam minha proposição.

Não obstante, a associação de Massao Ohno à categoria de editor híbrido, conforme proposto, suscita uma nova discussão: a postura adotada pelo editor paulistano configuraria sua editora como uma casa editorial independente, isto é, mantenedora de práticas que a colocariam como uma instituição que atuou à margem do grande mercado? E qual seria exatamente essa noção de independência que, segundo hipótese, orientou à práxis editorial de Massao Ohno?

Em tese sobre aspectos da produção editorial independente na Argentina e no Brasil, o pesquisador e professor José de Souza Muniz Jr. apresenta um quadro geral do conceito de independência relacionado à cultura e, por consequência, aplicável à própria literatura:

Em termos muito gerais, a produção cultural independente será concebida como aquela que está fora - mainstream ora por escolha, ora por condição - dos circuitos e mercados massivos; que não adota as lógicas dos grandes conglomerados de cultura e mídia; que se identifica com métodos artesanais de produção, com o experimentalismo estético e/ou com discursividades dissonantes, alternativas, contra-hegemônicas. Ao mesmo tempo que se opõe implicitamente ao dependente (ou seja, 
aos agentes e às práticas culturais subordinados a tais lógicas), esse produtor se definirá a contrapelo de certos carrascos da dependência o mercado, as empresas privadas, os grandes conglomerados, as instâncias públicas etc. que controlam a produção, a circulação e a consagração dos bens simbólicos. (MUNIZ JR., 2016, p. 16).

Nota-se que a concepção de independência editorial que vem sendo delineada e sugerida como caracterizante da Editora Massao Ohno até o momento neste trabalho - isto é, uma postura que coloca a empresa fora do circuito dominado pelas grandes casas editoriais e livrarias primando pela publicação de autores iniciantes com impressões de qualidade apurada a despeito da baixa tiragem - encontra uma síntese perfeita nos apontamentos de Muniz Jr. Nesse sentido, tal postura independente revela-se como uma espécie de "contraedição", que nega e busca alternativas àquelas impostas pelo grande circuito comercial de forma massiva.

Para os pesquisadores Hernán López Winne e Víctor Malumían a edição independente estaria associada a algumas condições.

El primer asunto que acude a la mente cuando se habla de independencia es la relación con el mercado. Un editor independiente debe pensar su catálogo ligado a coherencia de su contenido y no a las modas temáticas que atraviesan el mercado editorial. Debe, en todo momento, apostar a un catálogo de fondo y cada nueva publicación necesita discutir, dialogar, hacer sistema con los anteriores títulos del catálogo. [...] La coherencia no está limitada a publicar lo mismo, sino a trazar líneas de intercambio entre los distintos textos. (WINNE, MALUMÍAN, 2016, p. 4-5).

Destaca-se na proposição mencionada a importância dispendida à formação do catálogo da casa editorial de cunho independente. Sob a perspectiva apresentada, as obras escolhidas para formar esse catálogo ideal devem se inter relacionar com outros trabalhos editados pela casa, assegurando-lhe dessa maneira, coesão, coerência, unidade, o que conferiria identidade à editora. Nesse sentido, a Editora Massao Ohno também poderia ser caracterizada como independente, já que a opção por publicar ao longo de toda sua existência predominantemente títulos de poesia de autores das novas gerações, pode ser lida 
como tentativa de formar exatamente um catálogo cuja unidade pudesse facilitar a disseminação dessas obras pelo campo literário, contribuindo consequentemente para a constituição desse último.

Ainda sobre a questão da edição independente, absolutamente pertinente à travessia editorial de Massao Ohno segundo tem sido aqui sugerido, a pesquisadora Alice Bicalho de Oliveira apresenta valiosas reflexões em artigo que discorre acerca da independência como um modo de produção:

Há certa amplidão de definições do termo "independente" no contexto das produções culturais. Um dos sentidos com que, historicamente, a expressão está relacionada consiste nos modos de produção artística e cultural que se realizam desvinculados ou em oposição às grandes empresas da indústria cultural. No que diz respeito ao livro, se tomarmos como exemplo o que na Europa já vinha se organizando desde o século XIX, a indústria se estrutura a partir de grandes - e cada vez maiores oligopólios associados ao capital de outros tipos de indústria, com tamanha força econômica, que brecam o desenvolvimento de empresas menores e estruturadas com bases diferentes destes acordos comerciais e desta circulação de capital. As transformações expressivas nos modos de produção editorial ocorridas na passagem de uma produção mecanizada para os desenvolvimentos técnicos posteriores alteraram intensamente o universo editorial, desde a concepção de um projeto de livro a ser publicado até o estabelecimento dos direitos de autor, tiragens e modos de venda. A partir daí a história do livro vê certos esquemas de cooperação e troca entre editores serem esquecidos, e uma especialização e profissionalização cada vez maiores dos seus atores. Esta tendência não se desfez, pelo contrário, continua a crescer e a receber reforços de outras indústrias, agora das comunicações e tecnologias de informação. Diante deste universo podemos delimitar um primeiro campo para a compreensão do significado do termo "independente", qual seja, a oposição a um modelo industrial de produção, de vínculos entre grandes empresas, e de seus acordos financeiros. (OLIVEIRA, 2016, p. 79-80).

De acordo com as observações da pesquisadora, o termo em questão traz uma amplitude de definições, o que só evidencia o problema de fixar qualquer taxionomia de forma mais assertiva em relação ao tema. No entanto, pode ser destacada das palavras de Oliveira uma característica que, já sugerida nas citações anteriores, praticamente define a configuração das editoras independentes e que entendo ser aplicável à Editora Massao Ohno: a negação de modelos 
industrializados de produção, o que acarretaria, em consequência, a desvinculação dessas editoras independentes do domínio dos grandes oligopólios.

No começo da Editora, materializada no fim da década de 1950 a partir da pequena gráfica em um casarão na Rua Vergueiro em São Paulo, Massao elaborava e publicava os trabalhos dos jovens autores à época, ademais de imprimir as apostilas para cursinhos que eram naquele momento inicial, a principal fonte de renda do pequeno empreendimento. Mais tarde, talvez para manter a independência editorial - sobretudo no sentido criativo - e a estabilidade da empresa, buscando ampliar a quantidade, a variedade e a qualidade dos textos dos autores publicados, além de lhes proporcionar uma melhor circulação, mesmo que restrita às especificidades do campo literário em questão, Ohno se aliou a outros editores para incrementar sua atividade conforme também já observado.

Ainda segundo a pesquisadora e professora Ana Bicalho de Oliveira:

[...] a gama de editores que podem se considerar independentes é enorme, especialmente no Brasil, país em que o número de grandes grupos editoriais vinculados a capitais de outros tipos de indústria nacionais ou internacionais - organizados em políticas de desenvolvimento do setor é bem inferior ao número de editores que trabalham na base do "cada um por si", sofrendo o enorme impacto da competição desequilibrada com estes poucos (mas) gigantes da edição. Nesse sentido, portanto, podemos considerar editores independentes numa escala macroscópica as editoras de grande porte que só se estruturam financeiramente por meio da venda de livros; em outra escala, os editores de médio e pequeno porte que se organizam em ligas, mas se mantêm independentes em termos de capital e de competição de mercado, e microscopicamente uma enormidade de pessoas físicas que produzem livros artesanais e os comercializam em pontos de cultura das grandes cidades. Em outras palavras, esta primeira ideia de "independência" aponta para um modo de relacionamento entre empresas e capitais, não tecendo qualquer relação com o modo de produzir ou o tipo de produto final e, por isso mesmo, permite que coloquemos em um mesmo grupo "de independentes" formas muito distintas de editar e uma gama enorme de livros. (OLIVEIRA, 2016, p. 79-80).

A taxionomia proposta por Oliveira apresenta a edição independente dividida em três variantes ou escalas, todas coexistentes: a macroscópica, que envolve 
paradoxalmente as editoras de grande porte; uma intermediária, que encerra os editores de empresas medianas e pequenas cujas estratégias adotadas se baseiam na constituição de uma rede de circulação à margem do mercado como aposta de sobrevivência; e as microeditoras, ou editoras de um "homem só", que operam radicalmente à margem do mainstream cultural, adotando práticas de edição próximas às artesanais para elaborar obras dirigidas a um público leitor seleto.

Nesse sentido, a práxis editorial de Massao Ohno, conforme sugerido até o momento, se aproximaria à segunda categoria elaborada por Oliveira, mas com alguns traços da artesania inerentes à terceira variante. E isso porque a Editora de Ohno, de acordo com o levantado, ademais de dispender sensível cuidado para com a seleção e apresentação de seus constructos de acordo com o que será demostrado logo mais adiante, nunca cultivou, em relação ao mercado, uma atitude de total isolamento. A colaboração com outros editores para viabilizar os projetos de sua casa confirmam a preocupação de que as obras publicadas circulassem de maneira efetiva no campo literário.

Uma vez já deslindadas e correlacionadas algumas categorias de editor e independência, categorias essas que estão auxiliando a traçar um perfil um pouco mais claro da editora capitaneada por Massao Ohno, cabe lançar luz sobre mais uma ferramenta analítica no sentido de tentar compreender um pouco melhor a travessia da editora de Ohno no seu contexto de atuação: o conceito de campo ${ }^{1}$, além das ideias de habitus e capital simbólico, desenvolvidas por Pierre Bourdieu nas obras A economia das trocas simbólicas (2013), o poder simbólico (1998) e As regras da arte (1996). A pesquisadora Elaine Aparecida Teixeira Pereira,

\footnotetext{
${ }^{1}$ Em termos analíticos, um campo pode ser definido como uma rede ou uma configuração de relações objetivas entre posições. Essas posições são definidas objetivamente em sua existência e nas determinações que elas impõem aos seus ocupantes, agentes ou instituições, por sua situação (situs) atual e potencial na estrutura da distribuição das diferentes espécies de poder (ou de capital) cuja posse comanda o acesso aos lucros específicos que estão em jogo no campo e, ao mesmo tempo, por suas relações objetivas com outras posições (dominação, subordinação, homologia etc.). (BOURDIEU apud BONNEWITZ, 2005, p. 60).
} 
estudiosa das teorias do autor francês, propõe de maneira sintética uma noção mais geral desse tema:

Campo é um microcosmo social dotado de certa autonomia, com leis e regras específicas, ao mesmo tempo em que influenciado e relacionado a um espaço social mais amplo. É um lugar de luta entre os agentes que o integram e que buscam manter ou alcançar determinadas posições. Essas posições são obtidas pela disputa de capitais específicos, valorizados de acordo com as características de cada campo. Os capitais são possuídos em maior ou menor grau pelos agentes que compõem os campos, diferenças essas responsáveis pelas posições hierárquicas que tais agentes ocupam. (PEREIRA, 2015, p. 341).

Infere-se, a partir da síntese apresentada pela pesquisadora, que o campo é uma estrutura que, apesar de deter uma certa autonomia no corpo político/social, apresenta-se condicionado a uma série de delimitações e hierarquizações que estão entrelaçadas e ajudam a estruturar amplamente esse mesmo contexto. Em palestra ministrada sobre as teorias de Pierre Bourdieu, o historiador Roger Chartier, ainda que indiretamente, parece corroborar com a leitura da teoria do sociólogo francês feita pela pesquisadora. Para o historiador, também francófono,

[...] os campos, segundo Bourdieu, têm suas próprias regras, princípios e hierarquias. São definidos a partir dos conflitos e das tensões no que diz respeito à sua própria delimitação e construídos por redes de relações ou de oposições entre os atores sociais que são seus membros. (CHARTIER, 2002).

Interessante notar que a proposição de Bourdieu, sob o ponto de vista de Chartier, não escamoteia as tensões e oposições advindas das relações no campo, apesar da aparente regulamentação. Pelo contrário, ressalta que tais forças, por vezes antagônicas, são as que exatamente amalgamam as estruturas, fortalecendo por conseguinte a materialização do campo. Pierre Bourdieu delimitou, em seus estudos, alguns tipos de campo: o econômico, o religioso, o acadêmico, o artístico, o literário etc. São exatamente esses últimos que interessam sobremaneira a essa pesquisa devido a natureza artístico/literária do corpus - os livros publicados pela Editora Massao Ohno. Para o sociólogo francês 
o campo literário e artístico atrai e acolhe agentes muito diferentes entre si por suas propriedades e suas disposições, portanto, por suas ambições, e com frequência bastante providos de confiança e segurança para recusar contentar-se com uma carreira de universitário ou de funcionário e para enfrentar os riscos dessa profissão que não é uma profissão. (BOURDIEU, 1996, p. 256).

Sob essa perspectiva, pode ser dito que, ainda que o campo literário apresentese como estrutura multifacetada, pois é constituído a partir das ambições e ações de vários agentes, sua materialidade se fortalece exatamente a partir de um conjunto de ações com objetivos em comum. No caso da Editora Massao Ohno, tanto seu editor, como seus editados, além, é claro, do público leitor, constituíram a matéria-prima desse corpo de agentes, responsável por tecer uma espécie de rede produtora e divulgadora de uma parte da produção literária de então.

Cabem, ainda, mais algumas palavras sobre o conceito de campo. Para Bourdieu, o "campo, no seu conjunto, define-se como um sistema de desvio de níveis diferentes e nada, nem nas instituições ou nos agentes, nem nos atos ou nos discursos que eles produzem, têm sentido senão relacionalmente, por meio do jogo das oposições e das distinções". (BOURDIEU, 1996, p. 47). Sob essa perspectiva, a interação entre editor, autores e público isto é, a conexão entre os agentes do campo, ainda que diversa, múltipla, mediada e dada por meio de relações por vezes harmoniosas, por vezes tensas, coloca-se como condição imprescindível à manutenção do próprio campo.

Intimamente relacionado às noções de campo, está o conceito de habitus. De acordo com o próprio Bourdieu, o habitus poderia ser entendido "como sistema das disposições socialmente constituídas que, enquanto estruturas estruturantes, constituem o princípio gerador e unificador do conjunto das práticas e das ideologias características de um grupo de agentes" (BOURDIEU, 1996, p. 191). Destaca-se mais uma vez nas palavras do pesquisador, a importância dos agentes para a manutenção das estruturas as quais o habitus se relaciona. Nesse sentido, o habitus representado pelas práticas editoriais de Massao Ohno, que se posicionou como editor independente ao longo de sua travessia justamente 
buscando outras formas de publicação e circulação de seus produtos, evitando as fórmulas de produção e distribuição em massa impostas pelo mercado, proporcionou o incremento do campo literário no qual se desenvolveu.

Outro conceito importante ligado às ideias de campo e de habitus é o de capital simbólico. De acordo com Bourdieu, o capital simbólico ${ }^{2}$ não seria

[...] outra coisa senão o capital, qualquer que seja a sua espécie, quando percebido por um agente dotado de categorias de percepção resultantes da incorporação da estrutura da sua distribuição, quer dizer, quando conhecido e reconhecido como algo de óbvio. (BOURDIEU, 1996, p. 101).

Pode ser dito, tomando-se as palavras de Bourdieu como guia, que Massao Ohno foi exatamente um desses agentes cultivadores do capital simbólico, pois percebeu haver uma demanda de algo óbvio a ser explorado no contexto de então: a publicação de obras literárias de autores iniciantes na cidade de São Paulo no início da década 1960. Em entrevista para o livro Os dentes da memória, Ohno comentando esse momento inicial de sua editora, corrobora a proposição:

Evidentemente, se esses autores não eram conhecidos, tampouco consagrados, não poderiam ter um público leitor muito grande. Então, as tiragens eram mínimas. Algo como quinhentos ou mil exemplares. Dois mil numa exceção. A única maneira de esses livros terem saída era propagar essa ideia de renovação junto às escolas e núcleos estudantis com jovens que pudessem aceitar esses autores como parte de sua geração, gente que ainda estava no colégio ou prestes a ingressar nas faculdades. (OHNO apud D'ELIA, HUNGRIA, 2011, pp. 18-19).

Sob tal perspectiva, pode ser concluído que a estratégia de atuação, o habitus empreendido pelo editor Massao Ohno - que deu guarida ao trabalho de jovens nomes que se iniciavam na cena literária de São Paulo no início da década de 1960

\footnotetext{
${ }^{2}$ A pesquisadora Pascale Casanova, na obra A República Mundial das Letras (2002) também propôs algumas reflexões sobre a noção de capital cultural. Porém ela definiu sua visão sobre a composição desse tipo de constructo a partir das observações tecidas pelo poeta francês Paul Valéry sobre o assunto: "Do que é composto esse capital, Cultura ou Civilização?", insiste Valéry. "Antes de tudo, é constituído de coisas, de objetos materiais - livros, quadros, instrumentos etc., que têm sua duração provável, sua fragilidade, sua precariedade de coisas". No caso preciso da literatura, esses "objetos materiais" são, em primeiro lugar, os textos classificados, registrados e declarados nacionais, os textos literários reconvertidos em história nacional." (CASANOVA, 2002, p. 29).
} 
até praticamente o ano de seu falecimento, em 2010 - possibilitou a inserção desses novos autores no campo artístico/literário ao longo desse período. A injeção de capital simbólico, proveniente da publicação do trabalho desses autores pelas mãos de Ohno, acabou por proporcionar incremento significativo do campo literário brasileiro nessas últimas cinco décadas.

Nos conceitos até o momento apresentados, subjaz a ideia de que atividade literária, fomentada pela edição de obras do gênero, seria algo de caráter coletivo, práxis constituída a partir de uma trama, de uma rede, na qual as figuras do editor, do autor e do público estão inequivocamente interligadas. Outro estudioso que se dedicou a investigar as relações entre a literatura e seu contexto de existência e atuação foi o professor e pesquisador brasileiro Antonio Candido. A pesquisadora Susani Silveira Lemos França, em trecho do posfácio para uma das edições da obra de Candido intitulada Literatura e sociedade (2000) resume algumas das proposições do autor sobre o tema:

Candido explica que, do ponto de vista sociológico, a arte ou a arte literária, por ser um sistema simbólico de comunicação inter-humana, subentende a articulação permanente entre esses três elementos, que mutuamente conferem sentido uns aos outros, ajudando a compreender, se não a essência da arte, ao menos a formação e o destino das obras. [...] A partir da referida tríade, autor-obra-público, ele busca apontar as condições da produção literária no país [...] (FRANÇA apud CANDIDO, 2000, pp. 179-180).

Destaca-se no excerto apresentado a questão da articulação existente entre alguns elementos, o autor, a obra e o público, que são exatamente os constructos constituintes do campo literário. Nesse sentido, essa multiplicidade de vozes, essa pluralidade de agentes, uma vez mais, pode ser considerada como linha de força bastante importante para a manutenção do campo. É o próprio Antonio Candido que continua a deslindar algo sobre as relações entre autores, obra e seu público.

As relações entre o artista e o grupo se pautam por esta circunstância e podem ser esquematizadas do seguinte modo: em primeiro lugar, há a necessidade de um agente individual que tome a si a tarefa de criar ou apresentar a obra; em segundo lugar, ele é ou não reconhecido como 
criador ou intérprete pela sociedade, e o destino da obra está ligado a esta circunstância; em terceiro lugar, ele utiliza a obra, assim marcada pela sociedade, como veículo das suas aspirações individuais mais profundas. (CANDIDO, 2000, p. 23).

Sob a perspectiva de Candido, esse agente individual, criador de uma obra que Ihe proporciona reconhecimento no campo em que atua, isto é capital simbólico - aqui entendido no sentido proposto por Bourdieu - seria o autor. Outro elemento de destaque nessa tríade, segundo o pesquisador brasileiro, seria a obra. Para o autor do seminal Formação da literatura brasileira,

A obra, por sua vez, vincula o autor ao público, pois o interesse deste é inicialmente por ela, só se estendendo à personalidade que a produziu depois de estabelecido aquele contato indispensável. Assim, à série autor-público-obra, junta-se outra: autor-obra-público. Mas o autor, do seu lado, é intermediário entre a obra, que criou, e o público, a que se dirige; é o agente que desencadeia o processo, definindo uma terceira série interativa: obra-autor-público. (CANDIDO, 2000, pp. 33-34).

Conforme as palavras de Candido, a obra teria essa propriedade de amalgamar o autor e esse terceiro elemento, o público. Ou seja, a obra, sob esse ponto de vista, seria o elemento catalisador, no campo literário, dos anseios do autor e também de seu público. No caso da atuação da Editora Massao Ohno, às três categorias elencadas por Candido, acrescento uma quarta, a do editor, que sob a perspectiva oferecida nesta pesquisa, pode ser visto também como um autor, logo, também um catalisador, um fomentador central do campo literário. As relações advindas entre o editor paulista, os autores, as obras e o público permite vislumbrar tal proposição.

Para Antonio Candido,

A literatura é pois um sistema vivo de obras, agindo umas sobre as outras e sobre os leitores; e só vive na medida em que estes a vivem, decifrando-a, aceitando-a, deformando-a. A obra não é produto fixo, unívoco ante qualquer público; nem este é passivo e homogêneo, registrando uniformemente o seu efeito. São dois termos que atuam um sobre o outro, e aos quais se junta o autor, termo inicial desse processo de circulação literária, para configurar a realidade da literatura atuando no tempo. (CANDIDO, 2000, p. 68). 
Se para Candido a literatura é um sistema vivo, Massao Ohno foi, sem sombra de dúvidas, um de seus agentes mais ativos no sentido de alimentar tal vivacidade. Valendo-se de estratégias como o foco na divulgação de novos autores e o estabelecimento de parcerias com outros editores, conseguiu trazer ao campo literário, ainda que muitas vezes à margem do grande mercado editorial, publicações nas quais podem ser percebidos o apuro e o cuidado investidos para a materialização de tais constructos livrescos. Nesse sentido, a trajetória de sua Editora, orientada fortemente por um modus operandi característico das editoras independentes, ainda que com suas devidas contradições e idiossincrasias, contribuiu para trazer à luz um sistema vivo de obras que, agindo umas sobre as outras, em circunvoluções surgidas entre editor, autores e leitores, contribuiu de forma marcante para o incremento do campo literário brasileiro.

\section{REFERÊNCIAS}

ARAÚjO, Emanuel. A construção do livro. $2^{\text {a }}$ ed. Rio de Janeiro: Lexinkon Editora Digital; São Paulo: Fundação Editora da Unesp, 1986.

BONNEWITZ, Patrice. Primeiras lições sobre a sociologia de Pierre Bourdieu. Petrópolis: Vozes, 2005.

BOURDIEU, Pierre. A Economia das Trocas Simbólicas. Trad. Sérgio Miceli et alii. Introdução Sérgio Miceli. São Paulo: Perspectiva, 2013.

BOURDIEU, Pierre. As Regras da Arte: Gênese e Estrutura do Campo Literário. Trad. Maria Lúcia Machado. São Paulo: Companhia das Letras, 1996.

BOURDIEU, Pierre. O Poder Simbólico. Trad. Fernando Tomaz. $2^{\mathrm{a}}$ ed. Rio de Janeiro: Bertrand Brasil, 1998.

CANDIDO, Antonio. Formação da literatura brasileira: momentos decisivos. $6^{\mathrm{a}}$ ed. Belo Horizonte, MG: Editora Itatiaia, 1981.

CANDIDO, Antonio. Literatura e sociedade. 8ª edição. São Paulo: Publifolha, 2000.

CASANOVA, Pascale. A república mundial das letras. Trad. Marina Appenzeller. São Paulo: Estação Liberdade, 2002. 
CHARTIER, Roger. Pierre Bourdieu e a história. Palestra proferida na UFRJ, Rio de Janeiro, 30 abr. 2002.

D’ELIA, Renata. HUNGRIA, Camila. Os dentes da memória. São Paulo: Azougue Editorial, 2011.

FRANÇA, Susani Silveira Lemos. Antonio Candido: um crítico que fez história. In: CANDIDO, Antonio. Literatura e sociedade. $8^{a}$ edição. São Paulo: Publifolha, 2000.

HALLEWELL, Laurence. O livro no Brasil: sua história. Trad. Maria da Penha Villalobos, Lóio Lourenço de Oliveira e Geraldo Gerson de Souza. 3ª ed. São Paulo: Edusp, 2017.

HOUAISS, Antônio. Elementos de bibliologia. Rio de Janeiro: Instituto Nacional do Livro, 1968.

HOUAISS, Antônio. Dicionário eletrônico Houaiss da língua portuguesa. Manaus: Editora Objetiva, 2009.

KNAPP, Wolfgang. O que é editora? São Paulo: Brasiliense, 1986.

MASSAO OHNO: poesia presente. Direção: Paola Prestes. Codireção: Juliana Kase. São Paulo: Serena Filmes, 2015. 1 DVD (90 min.).

MELLO, Heitor Ferraz. O editor dos Novíssimos. In: Revista da Biblioteca Mário de Andrade. São Paulo: Departamento Biblioteca Mário de Andrade. Volume 65, novembro de 2009.

MUNIZ JR., José de Souza Muniz. Girafas e bonsais: editores “independentes" na Argentina e no Brasil (1991-2015). Tese (Doutorado em Sociologia) - USP, São Paulo, 2016. Disponível em: https://www.teses.usp.br/teses/disponiveis/8/8132/tde-28112016103559/pt-br.php. Acesso em 20 jul. 2020.

OLIVEIRA, Ana Bicalho de. A independência é um modo de produção. Em Tese. Belo Horizonte, v. 22, n.3, pp.79-89, set./dez. 2016.

PEREIRA, Elaine Aparecida. O conceito de campo de Pierre Bourdieu: possibilidade de análise para pesquisas em história da educação brasileira. Revista Linhas. Florianópolis, v. 16, n. 32, p. 337-356, set./dez. 2015.

PIGNATARI, Décio. O que é comunicação poética. 8a ed. Cotia, SP: Ateliê Editorial, 2005.

SILVA, José Armando Pereira da. Massao Ohno, editor. Cotia, SP: Ateliê Editorial, 2019.

WINNE, Hernán López; MALUMIÁN, Víctor. Independientes, ¿de qué? Hablan los editores de América Latina. México: FCE, 2016.

\section{Leonardo David de Morais}

Mestre em Estudos de Linguagens

https://orcid.org/0000-0002-6985-865X •leodemorais@gmail.com 